\title{
LYCIUM ISTHMENSE (SOLANACEAE), NUEVA ESPECIE DEL ISTMO DE TEHUANTEPEC
}

\author{
Fernando Chiang C.*
}

\section{Lycium isthmense Chiang, sp. nov.}

Frutex parce armatus vel inermis $1-2 \mathrm{~m}$. altus, aliquantum scandens. Rami extendentes flexuosi nodis floccosis. Folia fasciculata spathulata glabra $10-20 \quad(-35) \mathrm{mm}$. longa, (2-) $4.7 \quad(-12) \mathrm{mm}$. lata, ad apicem anguste vel late rotundata; marginibus ad basin sensim vel abrupte in gracilem petiolum decurrentibus; petiolus sparsim puberulus. Flores ad fasciculos foliorum so-

- litarii; pedicelli filiformes $8-20 \mathrm{~mm}$. longi. Calyx campanulatus 3-4 mm. longus, lobis 4 vel 5 triangularibus $1-1.5 \mathrm{~mm}$. longis acutis apicibus pubescentibus. Corolla rotata campanulata; tubus $4-5 \mathrm{~mm}$. longus, extus glabratus, intus pubescens juste supra staminum affixionem; lobi 4 ( raro 5), 2.5-3mm. longi, violacei venis brunneis, ovati apice rotundati margine ciliati alibi glabrati. Stamina suhinaequalia excerta lobis corollae aequantia vel paululum superantia: filamenta in dimidio superiore tuli affixa circa $4 . \mathrm{mm}$. e basi, dense pilosa in quarte parte inferiore; stylus staminibus acquans. Bacca rubra ovoidea 7-9 mm. longa, 5-6 $\mathrm{mm}$. lata, multiseminifera. Chromosomatum numerus $n=12$.

Arbusto escasamente espinoso o inerme, de 1-2 m. de alto, algo escandente, con ramas flexuosas extendidas y nudos floculentos. Hojas fasciculadas, espatuladas, glabras, de 10-20 (-35) mm. de largo, y (2-) 4-7 (-12) mm. de ancho, desde angosta hasta ampliamente redondeadas en el ápice (algunas hojas con ápice agudo), con márgenes decurrentes ya sea gradual o abruptamente hasta la base de un pecíolo delgado, éste escasamente puberulento. Flores solitarias en los fascículos foliares; pedicelos filiformes de $8-20 \mathrm{~mm}$. de largo. Cáliz campanulado. de $3-4 \mathrm{~mm}$. de largo, 4 ó 5-lobado, lohos triangulares, de $1.1 .5 \mathrm{~mm}$. de largo, agudos, con ápice piloso. Corola rotada-campanulada; tubo de la corola de 4-5 $\mathrm{mm}$. de largo, glabro externamente, piloso en al interior justamente encima de la unión de los estambres con el tubo; lobos de la corola 4, rara vez 5 , violáceos con venas pardas, ovados, redondeados en el ápice, de 2.5-3 mm. de largo, con márgenes esparcidamente ciliadas. Estambres ligeramente desiguales en longitud, igualando o sobrepasando ligeramente a los lobos de la corola.

* University of Texas at Autin. Department of Botany.

Chiang-C F. 1975. Lycium isthmense (Solanaceae), nueva especie del Itsmo de Tehuantepec. Boletín de la Sociedad Botánica de México 35: 3-5. 
éstos patentes, por lo cual los estambres son exsertos; filamentos adheridos a la mitad superior del tubo (aproximadamente $4 \mathrm{~mm}$. desde la base la corola), densamente pilosos en la cuarta parte inferior libre; anteras de $1 \mathrm{~mm}$. de largo. Estilo del mismo largo que los filamentos. Baya roja, ovoide, de $7-9 \mathrm{~mm}$. de largo y 5-6 mm. de ancho, con numerosas semillas. Número cromosómico tomado de células madres del polen, $\mathrm{n}=12$.

Esta especie parece tener sus afinidades más cercanas con $L$. carolinianum Walt., de la cual difiere en la mayor longitud del tubo de la corola en relación con los lobos, la unión de los filamentos con el tubo en la mitad superior de éste y las hojas delgadas, pecioladas y ampliamente espatuladas.

Arbusto común, cerca de la orilla de la laguna interior en la playa La Ventosa, aproximadamente $7 \mathrm{~km}$. al Este de Salina Cruz, Oax., en asociación con Conocarpus erectus, Prosopis juliflora, Pithecellobium sp., Junio 19, 1974, T. L. Wendt \& F. Chiang 315 HOLOTIPO (TEX); los isotipos serán distribuidos próximamente. Material adicional examinado: R. M. King 1554. (US), flat open grazed areas behind the beach of Laguna Superior, south of Juchitán, July 11, 1959; R. M. King 1303 (US), flat grazed areas behind the beach at La Ventosa, $7 \mathrm{Km}$ east of Salina Cruz, July 3, 1959; C. E. Smith, Jr., F. A. Paterson \& N. Tejeda 3678 (US).

Estoy profundamente agradecido al Sr. Thomas L. Wendt por el transporte proporcionado y la valiosa ayuda en la colecta de material y al Dr. Marshall C. Johnston por la corrección de la descripción latina y por su ayuda financiera por medio de una ayudantía de investigación en la Universidad de Texas en Austin. 


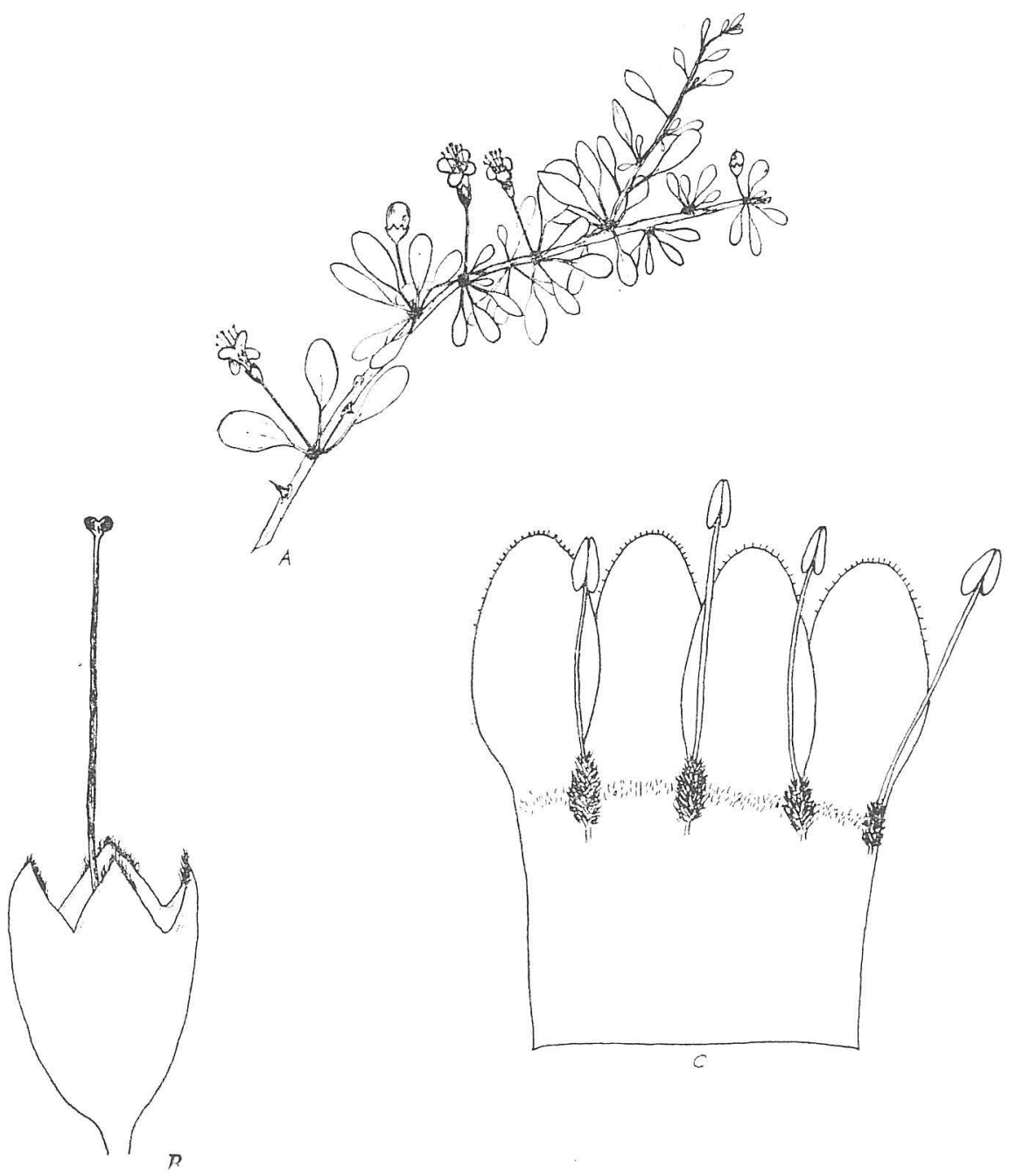

Lycium isthmense sp. nov.

Fig. A. Rama con flores y frutos. X 1 .

Fig. B. Cáliz y estilo. Aprox. X 11.

Fig. (.. Disección de la coroli. Aprox. X 11 . 